\title{
RURAL TOURISM: CROSSROADS BETWEEN NATURE, SOCIO-ECOLOGICAL DECOUPLING AND URBAN SPRAWL
}

\author{
CECILIA ARNAIZ-SCHMITZ ${ }^{1}$, LUIS SANTOS ${ }^{2}$, CRISTINA HERRERO-JÁUREGUI², PABLO DÍAZ ${ }^{3}$, \\ FRANCISCO D. PINEDA² \& MARÍA F. SCHMITZ ${ }^{2}$ \\ ${ }^{1}$ Universidad Autónoma de Madrid, Social-Ecological System Laboratory, Spain \\ ${ }^{2}$ Universidad Complutense de Madrid, ADAPTA Resercher Group, Spain \\ ${ }^{3}$ Ostelea-Universidad Juan Carlos I, Spain
}

\begin{abstract}
The development of cultural tourism has turned traditional rural landscapes, characterized by their great natural and cultural values, into focus of tourism attraction, causing important changes in the socioeconomic structure of the regions containing them. The enhancement of this tourism highlights the need to design and implement a sustainable management that guarantees the maintenance and conservation of the landscape and the economic development of local populations. This study, localised in the Lozoya Valley (Guadarrama Mountains, Central Spain), analyses the socio-ecological situation of its municipalities and visitors in two different times. The analysis of its temporal evolution has allowed us to notice a marked socio-ecological decoupling characterized by urban sprawl, loss of traditional landuses and practices and the rurality of local society. At the same time, a decrease is detected in the rural landscape valuation by visitors, increasing their preferences for naturalness. The conducted study is a novel contribution applicable to the conservative management of the landscape and the development of sustainable tourism for nature and society.
\end{abstract}

Keywords: conservative management, landscape dynamics, local socio-economy, multivariate analysis, rural tourism, sustainable tourism, typology of visitors.

\section{INTRODUCTION}

Cultural landscapes are conceived as 'social-ecological systems' [1] that represent a complex network of relations between nature and culture, biological and cultural diversity, tangible and intangible heritage and human identity [2]. Socio-ecological interactions convert cultural landscapes into dynamic systems in which their natural and socio-economic components coevolve [3], [4].

Degradation of the rural cultural landscape impacts on natural systems affecting their ability to supply the demand for ecosystem services on which human activities are based [5][7]. This problem has acquired great relevance in Mediterranean rural landscapes. Land uses and ecosystem services, associated with their millenarian landscapes, have been drastically modified, subjected to intense anthropogenic pressures linked to new socio-economic processes [8], [9]. Among them is the process of rural abandonment, which has favoured the loss of many of the traditional activities that have allowed the maintenance of historical cultural landscapes for centuries [10]-[12]. This has important ecological consequences such as biodiversity loss, increase of fire frequency and intensity, soil erosion and desertification, reduction of landscape diversity, reduction of water provision and loss of cultural and aesthetic values [13], [14].

The European Landscape Convention [15] defines the idea of landscape in this way: "an area perceived by people, whose character is the result of the action and interaction of natural and/or human factors". The perceptive nature of the landscape [16] and its dependence on the natural environment and cultural processes [17] has already been recognized. A landscape can be valued based on the subjective appreciation of its physical, biological and cultural 
components by human society. The development of cultural tourism has turned traditional rural landscapes, characterized by their great natural and cultural values, into focus of tourism attraction, causing important changes in the socio-economic structure of the regions containing them. Knowing the perception of the visitors of an area is a first step to land planning, management plans and decision-making that allow a sustainable, culturally equitable and economically profitable tourism development [18], [19].

The aim of this work is to determine both the socio-ecological dynamic experienced by a traditional rural landscape recognized as high tourist value and the change of the landscape valuation by visitors. In order to achieve this, the following specific objectives were addressed: i) Detect the variation in time of the coupling or linkage between the characteristics of the rural landscape and the socioeconomic structure of the local population, identifying the main social-ecological indicators of the linkage over a period of two decades; ii) in this landscape context, analyse the typology of visitors to the study area, their perception and preferences and the significant change in their landscape valuation according to the socio-ecological dynamics of the study area.

\section{METHOD}

\subsection{Study area}

The study area focuses on the Lozoya Valley, a mountain valley located in the northern Sierra de Guadarrama, in the Lozoya river basin (Madrid region, Spain) and includes 30 municipalities. Its altitude ranges from 1,100 to $2,400 \mathrm{~m}$ asl. The vegetation is characterized by Pyrenean oak (Quercus pyrenaica) and Scots pine (Pinus sylvestris) forests, Mediterranean shrublands and upland grasslands. In the lower areas, traditional silvo-pastoral systems ( $Q$. pyrenaica forestry-grazing) appear, with a heterogeneous mosaic of traditional land uses containing pastures, meadows, hedgerows, ash groves and riparian forests, all of which are well preserved in most cases.

The landscape structure of the area has been the result of ancient land use systems and rural activities that for centuries have been performed in the region contributing to their great socio-ecological value [20], which have made them worthy of different categories of protection. Thus, the Lozoya valley is within the boundaries of the Sierra de Guadarrama National Park (established in 2013) and the Sierra del Rincón Biosphere Reserve (2005). It belongs to the European network of protected sites Natura 2000 (Habitat Directive and Birds Directive), comprising an area classified as Site of Community Importance (SCI) and for Special Areas of Conservation (SAC) (Cuenca del río Lozoya y Sierra Norte) and a Special Area of Conservation for Birds (SPA) (High Valley of the Lozoya River).

Regarding the recognition of other categories of natural and cultural heritage, there are also several notable areas inside the valley as: i) Montejo de la Sierra beech forest, the most southern beech forest in Europe, declared as Natural Site of National Interest (by the Government of Spain in 1974) and World Heritage Site (by UNESCO, 2017); ii) Monastery El Paular, declared as Historical-Artistic Monument of Spain (by the Government of Spain, 1876); iii) the Neanderthals Valley, an upper Pleistocene archaeological site declared as Cultural Interest Good (by the Government of Spain, 2004); and iv) a proposed Geosite with International Significance (by the Geological and Mining Institute of Spain). Moreover, the High Valley of the Lozoya River has been proposed as a model of Heritage Cultural Landscape to UNESCO by the Spanish National Plan of Cultural Landscape (2012). Thus, the area is very appreciated by visitors to the Madrid region [21]. 


\subsection{Socio-ecological analysis}

We collected socio-ecological information from the valley using two types of descriptors: i) quantitative data of land use and land cover (LULC), recorded in 1989 and two decades later, 2010 [22]; and ii) socio-economic data of the local population at equivalent times (1990 and 2011) [23]. We consider the 30 municipalities of the valley as units of analysis because they constitute the smallest unit of governance and management in the Madrid region and also the most detailed level at which LULC and socio-economic census data are available [24], [25]. The data matrices analysed, $\left(\mathrm{m} \times \mathrm{d}_{\mathrm{L}}\right)$ and $\left(\mathrm{m} \times \mathrm{d}_{\mathrm{S}}\right)$, contained the set of municipalities described over time by means of 46 LULC and 27 socioeconomic descriptors, respectively. In order to quantify the relationship between LULC and socio-economic structures in time, we performed a Canonical Correspondence Analysis (CCA) to know the main links between both sets of descriptors [26], [27]. The CCA allows us to know the tendency and magnitude of the socio-ecological changes that occurred in each of them in the period of time elapsed.

\subsection{Classification of the visitors}

The landscape valuation of the Lozoya Valley by the visitors was examined through surveys carried out in two years (2007 and 2017). Questionnaires to visitors were conducted during weekends and vacation periods, from autumn to summer. The interviewed visitors were chosen randomly in the valley and their access routes in areas considered to be of particular interest for recreation and tourism. No more than two people were surveyed within each group of visitors. The questions did not refer only to those places, but rather to landscape characteristics of the whole valley. Visitors were asked about four classes of questions: i) sociological profile; ii) reasons for visiting the area; iii) landscape typology preferences; and iv) profile of intended activities.

The sampling work field implied 100 questionnaires per each year sampled. Two matrices of qualitative data, one for each year, $t_{1}$ and $t_{2}$, with 46 variables corresponding to the landscape preferences of the interviewees (iii-type) were set up. Types of visitors were obtained analysing the two matrices, $t_{1}$ and $t_{2}$, independently by means of a multivariate analysis of classification non-hierarchical K-means, using Wilks'lambda as optimization criterion. Groupings of visitors obtained were validated through Discriminant Analyses, applying the Rao's approximation.

Variables corresponding to questions (i), (ii) and (iv) were considered as external descriptors of each of the visitor types and tested by means of a $\chi^{2}$ analysis.

\section{RESULTS}

\subsection{Socio-ecological dynamics}

The first CCA axis shows the main change tendency of the rural landscape (29.90\% variance accounted for). Avoiding redundant results (axes 1 and 2 explain landscape variability in a very similar way), we focus only on the first axis, which describes the change of landscape during two decades and shows a gradient of socio-ecological decoupling and loss of rurality (Fig. 1). At the negative end, according to the loadings of the LULC descriptors, $\mathrm{d}_{\mathrm{L}}$, the axis highlights silvo-pastoral systems and, according to socio-economic descriptors, $\mathrm{d}_{\mathrm{s}}$, a rural society mainly dedicated to livestock farming. The positive end, on the contrary, is characterized by a noticeable shrub encroachment process linked to the abandonment of rural activities and urban sprawl, as well as to a high rent per capita of the local people (Fig. 1). 


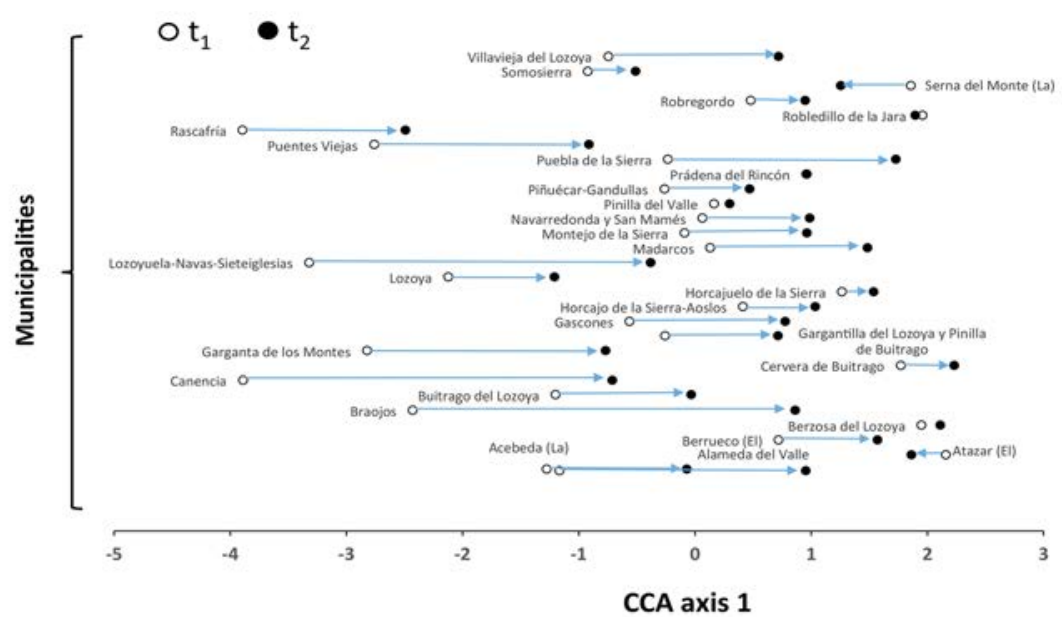
$d_{\mathrm{L}}$ \{ Silvo-pastoral systems
Socio-ecological decoupling
$d_{s}$ \{ Livestock farming
Rurality loss
$d_{L}\left\{\begin{array}{l}\text { Shrub encroachment } \\ \text { Urban systems }\end{array}\right.$
$d_{S}\{$ Rent per capita

Figure 1: Position of the municipalities of the Lozoya Valley along the main axis of a CCA. Above, the vertical distribution of the municipalities only corresponds to an alphabetical order). The analysis was performed simultaneously on two data matrices (municipalities $\mathrm{x}$ LULC descriptors), $\mathrm{d}_{\mathrm{L}}$, and (municipalities $\mathrm{x}$ socioeconomic descriptors), $d_{S}$. The five descriptors of higher loadings are displayed at the bottom of the figure. The coordinates of the municipalities on the CCA axis 1 are linked by arrows showing the direction and magnitude of the socio-ecological change from $t_{1}$ (LULC data of 1989 and socioeconomic data of 1990) to $t_{2}$ (2010 and 2011, respectively).

Along the CCA axis 1, we have drawn arrows joining the coordinates of the municipalities from $t_{1}$ to $t_{2}$. This has allowed us to know the direction and intensity of the socio-ecological change (the study period). The magnitude of the change has been great in municipalities such as Lozoyuela, Canencia or Braojos and little important in Robregordo, Horcajuelo de la Sierra or El Atazar, which remain almost unchanged over time.

\subsection{Characterization of visitors}

\subsubsection{Typology of visitors in 2007}

Four types of visitors were obtained: i) Natur-generalist visitors - 'Ecogeneralists' - (26\%), value any type of landscape with natural elements. They are people of mature age without special incentives to visit the area, although have a certain preference for activities related to nature, such as watching birds, other animals, vegetation, nature photography, ...; ii) Ruralnaturalist visitors $(25 \%)$, show preference for natural and rural-cultural landscapes. They are young people (16-24) who visit these places for their rural landscape, for sport or simply enjoy nature or have a picnic; iii) Family tourism visitors (21\%), attracted by both natural as cultural values, especially water landscapes; and iv) Indifferent visitors (28\%), with little motivation to visit the valley - a sociologically heterogeneous group, without concrete preferences for any landscape type or landscape component. 
Table 1(a) shows the two first discriminant functions indicating the degree of preference, indifference or rejection of a set of variables that represent characteristics of the landscape in 2007. The first discriminant function, F1, allowed us to detect on this date, by means of four landscape indicators (higher discriminant loadings), a gradient of visitor preferences for natural and rural characteristics of the landscape (Fig. 2(a)). Ecogeneralist (i) and RuralNaturalist (ii) visitors are those that show a greater appreciation for these aspects of the landscape.

\subsubsection{Typology of visitors in 2017}

One decade later, the analysis of the Lozoya valley visitors again detected four types, but some of their characteristics have clearly changed: i) Sports-generalist visitors (32\%) with a wide range of landscape preferences. This is a group formed only by women who play sports; ii) Naturalist visitors (31\%) show a clear preference for the naturalness of the landscape against its rurality. Members of this group are young people who practice cultural activities, nature photography, animal watching, picnics in nature, ...; iii) Family tourism visitors $(21 \%)$ value cultural and natural aspects of the territory. Their landscape preferences are related to vegetation and aquatic elements; and iv) Mountainous landscape visitors (16\%) prefer highaltitude landforms, water systems and cultural elements of landscape. They practice hiking and enjoy naturalness. Components of this group belong to a wide range of ages and have in common the city of Madrid as origin.

Table 1: Indicators of the landscape preferences of visitors in both times studied (2007 and 2017). They were obtained through Discriminant Analyses considering the valuations of landscape features. Loadings in F1 and F2 are indicated. 1 and 0 represent, respectively, preference (1) and rejection or indifference (0) in the valuation of the landscape variables.

\begin{tabular}{lclc}
\hline (a) 2007 & & & \\
\hline Variables & F1 & Variables & F2 \\
\hline Juniper groves-1 & -0.83 & Agricultural land mosaics-1 & -0.42 \\
Shrublands-1 & -0.82 & Rainfed crops-1 & -0.41 \\
Poplar and birch groves-1 & -0.81 & Irrigated crops-1 & -0.37 \\
\cline { 4 - 4 } Agricultural land mosaics-1 & -0.81 & Irrigated crops-0 & 0.37 \\
\hline Agricultural land mosaics-0 & 0.81 & Rainfed crops-0 & 0.41 \\
Poplar and birch groves-0 & 0.82 & Agricultural land mosaics-0 & 0.42 \\
Shurblands-0 & 0.82 & & \\
Juniper groves-0 & 0.83 & & \\
\hline
\end{tabular}

\begin{tabular}{lclc}
\hline (b) 2017 & & & \\
\hline Variables & F1 & Variables & F2 \\
\hline Ash tree forests-0 & -0.80 & Rainfed crops-1 & -0.70 \\
Pyrennean oak forests-0 & -0.78 & Agricultural land mosaics-1 & -0.65 \\
Holm oak forests-0 & -0.76 & Olive groves-1 & -0.63 \\
\hline Holm oak forests-1 & 0.76 & Olive groves-0 & 0.63 \\
Pyrennean oak forests-1 & 0.79 & Agricultural land mosaics-0 & 0.65 \\
Ash tree forests-1 & 0.80 & Rainfed crops-0 & 0.70 \\
\hline
\end{tabular}



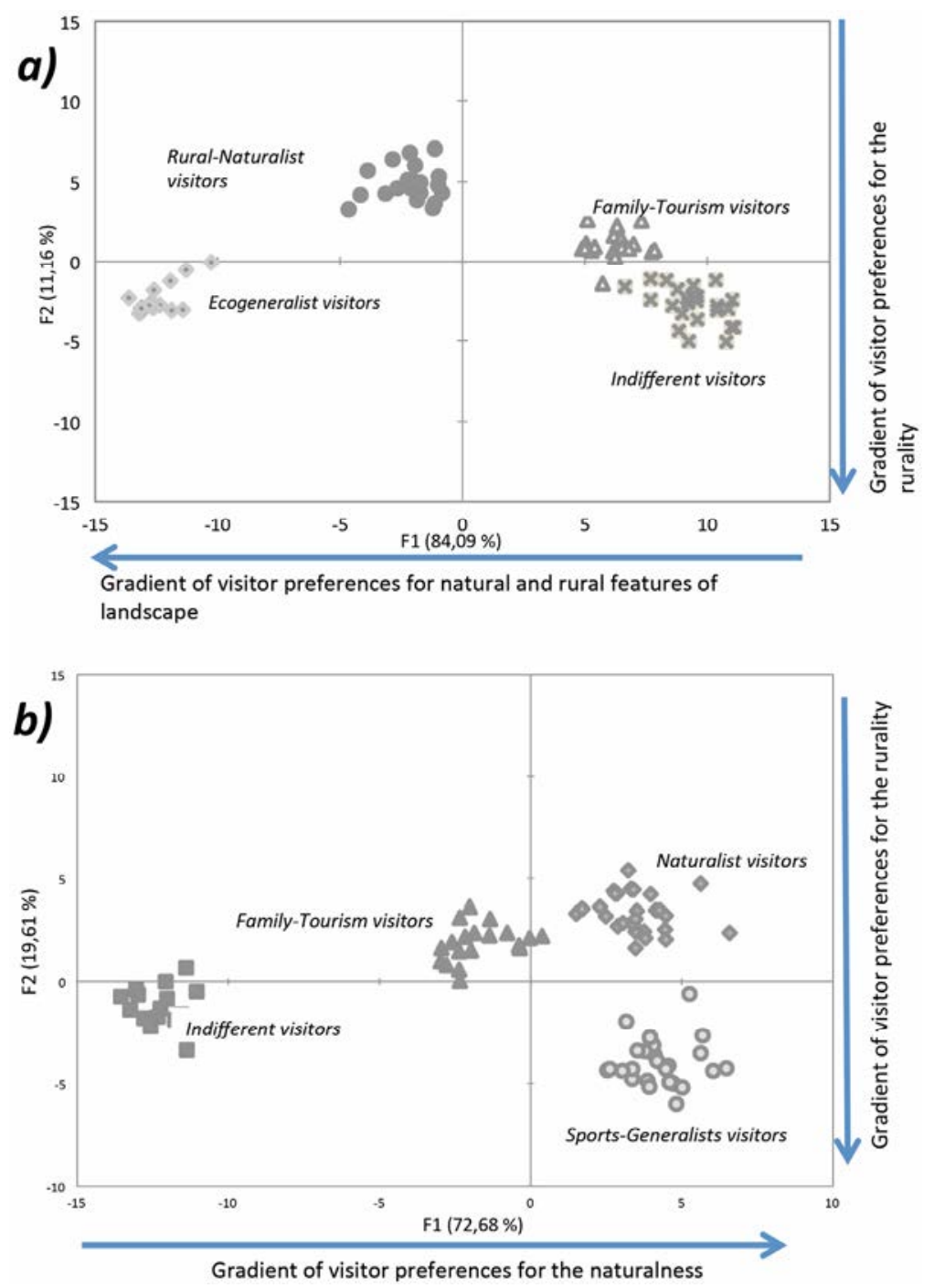

Figure 2: Discriminant analysis of the types of visitors to the Lozoya Valley. The two main landscape valuation tendencies are highlighted (obtained from the first two discriminant functions). a) 2007; b) 2017. See Table 1.

In Table 1(b), the variables with higher loadings in the discriminant function F1 are three landscape descriptors representing arboreal formations with a high degree of naturalness. In F2 also three variables are, in this case, indicators of the agricultural rural landscapes. The preferences of these landscape indicators segregate the types of visitors in the plane defined by the first two discriminant functions. F1 shows a gradient of preferences of visitors for naturalness and F2 shows a gradient of preferences for rurality (Fig. 2(b)). 


\section{DISCUSSION}

The ancient multifunctional landscape of the Lozoya Valley is characterized by a heterogeneous mosaic of traditional land use systems. This landscape has been generated through a complex network of biophysical and cultural processes which have resulted in a valuable heritage landscape [8], [16], [28]. Although conservation efforts to preserving this heritage landscape had been made at national and international level, management plans do not seem to have been adequate for the conservation objectives, putting at risk their continuity. Thus, the study of this landscape over time highlights an intense change both in land-use composition and socio-economy of the local population and, therefore, in the structure and functioning of the rural system.

The tendency of change varies from the traditional agrosilvopastoral system and livestock farming to shrub encroachment linked to the rural abandonment and urban sprawl. This has brought along a remarkable process of socio-ecological decoupling and loss of rurality in most of the municipalities of the valley.

In any case, the landscape is attractive for cultural tourism, their valuation by the visitors has changed over the period studied, although the tourist stereotypes have been maintained, finding both generalist and specialized visitors [24], [29]-[31]. In the first year studied, the types of visitors mainly differed from each other along a gradient of rural landscape assessment, expressed by the calculated first discriminant function $(84.09 \%$ explained variance). The preference for naturalness, summarized by the second discriminant function, is significantly lower (11.16\%). A decade later, an exchange of the landscape interests of the visitors is detected, acquiring a greater importance the naturalness $(72.68 \%$ variance absorption; first discriminant function) in front of the rurality (19.61\%; second function; Fig. 2(a), (b)).

\section{CONCLUSION}

The integrated study of the dynamics of the landscape structure of the Lozoya Valley and the socio-economy of its local population has allowed us to detect a clear tendency towards a socio-ecological decoupling characterized by the urban sprawl and the loss of both traditional land-use practices and rurality of the society.

Linked to a process of rural socio-ecological decoupling there are both a decrease in the valuation of the rural landscape by visitors and an increase in their preferences for naturalness. This indicates a certain ineffectiveness in the management of a heritage cultural landscape which includes categories of protection institutionally recognized as "of high ecological, natural and cultural value".

Results clearly show the need for this type of studies to manage and promote a culturalnatural tourism based on the maintenance of those traditional rural activities that generated this heritage cultural landscape, prioritizing its conservation, the nature protection and the economic development of local population.

\section{REFERENCES}

[1] Berkes, F., Colding, J. \& Folke, C. (eds.), Navigating Social-Ecological Systems: Building Resilience for Complexity and Change. Cambridge University Press: Cambridge, 2008.

[2] Rössler, M., World Heritage cultural landscapes: A UNESCO flagship programme 1992-2006. Landscape Research, 31, pp: 333-353, 2006. DOI: 10.1080/ 014263906010010.

[3] Norgaard, R.B., Coevolutionary development potential. Land Economics, 60(2), pp. 160-173, 1984. 
[4] Turner, R.K., Lorenzoni, I., Beaumont, N., Batemon, I.J., Langford, I.H. \& McDonald, A.L., Coastal management for sustainable development: analysis environmental and socioeconomic changes on the UK coast. The Geographical Journal, 164(3), pp. 269281, 1998.

[5] Assessment, Millennium Ecosystem, Ecosystem and Human Well-being: Biodiversity Synthesis. World Resources Institute: Washington, DC, 2005.

[6] Rockström, J. et al., A safe operating space for humanity. Nature, 461(7263), pp. 4725, 2009. DOI: 10.1038/461472a.

[7] Steffen, W. et al., Planetary boundaries: guiding human development on a changing planet. Science, 347(6323), p. 1259855, 2015. DOI: 10.1126/science.1259855.

[8] Bernáldez, F.G., Diversidad biológica, gestión de ecosistemas y nuevas políticas agrarias. Biological Diversity, eds F.D. Pineda, M.A. Casado, J.M. De Miguel \& J. Montalvo, Fundación Areces-SCOPE-WWF: Madrid, pp. 23-31, 1991.

[9] Bunce, R.G.H. et al. (eds), Examples of Agri-environment Schemes and Livestock Systems and their Influence on Spanish Cultural Landscapes. Alterra: Wageningen, 2001.

[10] Baldock, D., Beaufoy, G., Bennett, G. \& Clark, J. (eds), Nature Conservation and New Directions in the Common Agricultural Policy. Institute for European Environmental Policy: Arnhem, 1993.

[11] Bischoff, N.T. \& Jongman, R.H.G., Development of Rural Areas in Europe: The Claim for Nature. Netherlands Science Council for Government Policy: The Hague, 1993.

[12] Höchtl, F., Lehringer, S. \& Konold, W., 'Wilderness': what it means when it becomes a reality: a case study from the southwestern Alps. Landscape and Urban Planning, 70, pp. 85-95, 2005. DOI: 10.1016/j.landurbplan.2003.10.006.

[13] Jaeger, J.A., Landscape division, splitting index, and effective mesh size: new measures of landscape fragmentation. Landscape Ecology, 15(2), pp. 115-130, 2000. DOI: 10.1023/A:1008129329289.

[14] Benayas, J.R., Martins, A., Nicolau, J.M. \& Schulz, J.J., Abandonment of agricultural land: An overview of drivers and consequences. CAB Reviews: Perspectives in Agriculture, Veterinary Science, Nutrition and Natural Resources, 2(57), pp. 1-14, 2007. DOI: 10.1079/PAVSNNR20072057.

[15] Council of Europe, The European Landscape Convention. European Treaty Series, 76, Florence, 2000.

[16] Bernáldez, F.G., Ecología y Paisaje. Blume ed: Madrid, 1981.

[17] Naveh, Z., Interactions of landscapes and cultures. Landscape and Urban Planning, 32, pp. 43-54, 1995. DOI: 10.1016/0169-2046(94)00183-4.

[18] Naughton-Treves, L., Participatory zoning to balance the conservation and development in protected areas. Integrating Ecology and Poverty Reduction: The Application of Ecology in Development Solutions, eds C.J. Ingram, F. De Clerck \& C. Rumbaitis del Rio, Springer: New York, pp. 235-251, 2012.

[19] Faleiro, F.V. \& Loyola, R.D., Socioeconomic and political trade-off in biodiversity conservation: A case study of the Cerrado biodiversity hotspot, Brazil. Diversity and Distributions, 19(8), pp. 977-987, 2013. DOI: 10.1111/ddi.12072.

[20] Schmitz, M.F., Herrero Jáuregui, C., Arnaiz-Schmitz, C., Sánchez, I.A., Rescia, A.J. $\&$ Pineda, F.D., Evaluating the role of a protected area on hedgerow conservation: The case of a Spanish cultural landscape. Land Degradation \& Development, 8(3), pp. 833842, 2017. DOI: 10.1002/ldr.2659. 
[21] Schmitz, M.F., De Aranzabal, I. \& Pineda, F.D., Spatial analysis of visitors preferences in the outdoor recreational niche of Mediterranean cultural landscapes. Environmental Conservation, 34(4), pp. 300-312, 2007. DOI: 10.1017/S0376892907004249.

[22] SIGA, Sistema de Información Geográfica de Datos Agrarios 1989-2010, Mapa de Cultivos y Aprovechamientos. Ministerio de Agricultura Alimentación y Medio Ambiente. Response website, Madrid, 2011. www.sig.mapama.es/siga/.

[23] IECM, Statistical Institute of the Region of Madrid. Territorial Data Base 1999-2011. Response website, Madrid, 2011. www.madrid.org/iestadis/.

[24] De Aranzabal, I., Schmitz, M.F., Aguilera P.A. \& Pineda, F.D., Modelling of landscape changes derived from the dynamics of socio-ecological systems. A case of study in a semiarid Mediterranean landscape. Ecological Indicators, 8, pp. 672-685, 2008. DOI: 10.1016/j.ecolind.2007.11.003.

[25] Salvati, L. \& Serra, P., Estimating rapidity of change in complex urban systems: A multidimensional, local-scale approach. Geographical Analysis, 48, pp. 132-156, 2016. DOI: $10.1111 /$ gean.12093.

[26] Hotelling, H., Relations between two sets of variables. Biometrika, 28, pp. 321-377, 1936.

[27] Sherry, A. \& Henson, R.K., Conducting and interpreting canonical correlation analysis in personality research: A user-friendly primer. Journal of Personality Assessment, 84, pp. 37-48, 2005. DOI: 10.1207/s15327752jpa8401_09.

[28] Herrero-Jáuregui, C. et al., Heritage Cultural Landscape of Lozoya Valley (Central Spain): Methods and sources of spatial analysis. Topografía y Cartografía, 35(173), pp. 145-150. 2016.

[29] Gulinck, H., Vyverman, N., Van Bouchout, K. \& Gobin, A., Landscape as framework for integrating local subsistence and ecotourism: A case study in Zimbabwe. Landscape and Urban Planning, 53, pp. 173-182, 2001. DOI: 10.1016/S01692046(00)00152-3.

[30] Aguilera, P., Schmitz, M.F., De Aranzabal, I. \& Pineda, F.D., Characterization of visitors to natural areas in the southeast of Spain. Sustainable Tourism, eds C.A. Brebbia \& F.D. Pineda, Wessex Institute of Technology, WIT Press: Southampton, pp. 333-340, 2004.

[31] Schmitz, M.F., Fernández-Sañudo, P., De Aranzabal, I. \& Pineda, F.D., Visitor's valuation of natural and cultural landscapes: space-preferences coincidence analysis. Sustainable Tourism, eds C.A. Brebbia \& F.D. Pineda, Wessex Institute of Technology, WIT Press: Southampton, pp. 307-317, 2004. 